\title{
OBITUARI: NEUS GALÍ (1955-2019)
}

\author{
JAUME PÒRTULAS \\ Universitat de Barcelona \\ jportulas@ub.edu \\ ORCID: 0000-0003-3414-788X
}

El 6 de juliol del 2019, ara fa un any, va morir, a conseqüència d'un accident, Neus Galí Oromí. ${ }^{1}$ S'havia llicenciat en Filologia Clàssica (especialitat Llatí) a la Universitat de Barcelona el 1981, i doctorat en Filologia Clàssica, en aquesta mateixa Universitat, el 1998. Entre el 1992 i el 2014 va ésser professora a la Facultat d'Humanitats de la Universitat Pompeu Fabra.

Nascuda en el si d'una família molt vinculada al món de l'art, la cultura i la pedagogia (era neta del pintor Francesc d'Assís Galí Fabra i parenta de Pompeu Fabra i del pedagog Alexandre Galí), la Neus tenia una personalitat polifacètica i un temperament entusiasta i creatiu. Potser el tret més característic de la seva personalitat intel-lectual era la pluralitat d'interessos i la capacitat per a combinar-los sense aparent dificultat. Va dedicar la tesina i la tesi doctoral a estudiar la gènesi i el desenvolupament del topos clàssic «Ut pictura poiesis». En la tria d'aquest argument s'hi combinaven l'interès per les qüestions artístiques - vivíssim en ella al llarg d'aquells anys, fins i tot per motius personals - i una visió de la cultura d'arrel profundament humanística, en el sentit més ple d'aquest noble terme, sempre tan fàcil de banalitzar. Va centrar la tesina, d'orientació més estrictament filològica, en el poeta Simònides de Ceos (ca. $556 \mathrm{aC}$ - ca. 468), el creador, segons la tradició, de la famosa comparació entre poesia i pintura. Pel que fa a la tesi, va adoptar un to més assagístic i més filosòfic alhora; els dos qualificatius no resulten, en aquest cas, gens incompatibles, ben al contrari. L'espai més important hi era dedicat a l'estètica platònica; però també hi havia un apartat, especialment atractiu, sobre el sofista Gòrgias de Lentini (ca. $485 \mathrm{aC}$ - ca. 380).

La tesi de la Neus (que havia estat dirigida per la professora Dolors Oller, de la UPF, i per mi mateix, que ja li havia dirigit la tesina) fou publicada, amb veritable entusiasme, per Jaume Vallcorba a El Acantilado, amb el títol Poesía silenciosa, pintura que habla i el subtítol De Simónides a Platón. La invención del territorio artístico (1999). Va ésser un èxit de crítica, i crec que també de vendes. Pel que fa a la crítica, només vull recordar - a tall d'anècdota, però significativa - que algú va escriure que aquell llibre estava tan ben escrit que no semblava el resultat d'una tesi doctoral.

Les altres publicacions de Neus Galí també responen, en termes generals, a aquesta mateixa combinació de sensibilitat literària - i estètica, en general - , sincera devoció a la tradició clàssica i el determini de no posar obstacles innecessaris al common reader. Va arranjar una versió castellana dels Aurea Dicta que la Fundació Bernat Metge havia tret

\footnotetext{
${ }^{1}$ Agraeixo a la Redacció de l'Anuari de Filologia la invitació a escriure aquestes ratlles; i a Alícia Ferran Neira, cunyada de Neus Galí, i també antiga deixebla meva, que em fornís algunes informacions de tipus personal que m'han ajudat a redactar-les.
} 
a la llum el 1960, sota el pseudònim colllectiu de Jordi Lombard. També va preparar unes antologies força personals, traduïdes i anotades, de Virgili i Ovidi. Les va intitular Virgilio. De una antigua llama i Publio Ovidio Nasón. Mil formas de amor; foren publicades per Península el 2001 i el 2002, respectivament. En canvi, no es va prodigar gaire - i quan ho va fer, va ésser, en general, per necessitat i a contracor - en les publicacions especialitzades del gremi. Sentia un horror difícil de superar per la prosa adotzenada i repel-lent que sol gastar-s'hi.

A la Facultat d'Humanitats de la Universitat Pompeu Fabra hi va impartir, segons la nota necrològica divulgada per aquella institució, classes de cultura clàssica, de mitologia i de llatí. Les seves línies d'investigació principals foren les relacions entre oralitat i escriptura, i la poètica i la retòrica grecollatines. També va ésser membre del Grup de Recerca en Literatura Comparada. Hi va tenir molts, i molt entranyables, amics - com penso que li va passar en tots els indrets que freqüentava; però les darreres derives de les Universitats, aquí i pràcticament a tot arreu, en el sentit de l'extrema especialització, la competitivitat desfermada i la hiperproducció sense solta, acompanyada de la multiplicació d'instàncies avaluadores, acostumaven a deixar-la perplexa i escandalitzada. El 2014, es va acollir a la jubilació anticipada, per greus motius de salut.

Al llarg dels que, tan imprevisiblement, van resultar els darrers temps de la seva vida, esmerçà moltes hores amb un grup d'amics que, sota la direcció de Narcís Comadira, assajaven una traducció dels Ossi di seppia, l'extraordinari primer poemari d'Eugenio Montale. Vaig rebre d'ella alguns e-mails amb mostres de traduccions, preguntes, observacions i comentaris sobre la tria d'una paraula, el ritme d'una frase, la dificultat d'una expressió que no es deixava girar en català. La inesperada notícia de la seva mort, en el curs d'un viatge a Andalusia, va ésser un cop dur - per a mi i per a tantíssims altres, a jutjar per la gernació que omplia de gom a gom una de les més desolades cerimònies de comiat que hagi presenciat mai.

\section{BIBLIOGRAFIA}

GaLí, Neus (1994). Simónides de Ceos y la génesis del topos «Ut pictura poiesis», Barcelona, Universitat de Barcelona, Tesi doctoral (director Jaume Pòrtulas).

GALÍ, Neus (1998). «Ut pictura poiesis»: la génesis de un topos, Barcelona, Universitat de Barcelona, Tesi doctoral (directors Dolors Oller, Jaume Pòrtulas).

GaLí, Neus (1999). Poesía silenciosa, pintura que habla. De Simónides a Platón: La invención del territorio artístico, Barcelona, Acantilado.

GaLí, Neus (2001). Virgilio. De una antigua llama. Selección, traducción, presentación y apéndice de Neus Galí, Barcelona, Península.

Galí, Neus (2002). Publio Ovidio Nasón. Mil formas de amor, Barcelona, Ediciones Península.

LOMBARD, Jordi (1960). Aurea dicta. Paraules de l'antiga saviesa, Barcelona, Fundació Bernat Metge.

VALENTÍ, Eduard (1987). Áurea Dicta. Dichos y proverbios del mundo clásico. (Selección de Eduard Valentí. Traducción y complementos de Neus Galí. Introducción de Enrique Tierno Galván), Barcelona, Crítica. 